\title{
A RETROSPECTIVE STUDY OF EPIDEMIOLOGY FRACTURES OF MANDIBLE IN TERTIARY CARE TEACHING HOSPITAL OVER A PERIOD OF A DECADE
}

\author{
Gurram Rangaswamy1, Arige Subodh Kumar2, Gurram Manjula ${ }^{3}$, Pokkula Ramesh ${ }^{4}$ \\ ${ }^{1}$ Assistant Professor, Department of Plastic Surgery, Gandhi Medical College, Secunderabad. \\ ${ }^{2}$ Associate Professor, Department of Plastic Surgery, Gandhi Medical College, Secunderabad. \\ ${ }^{3}$ Ex-Resident, Apollo Hospital, Basavataraka Cancer Hospital, LV Prasad Eye Hospital, Hyderabad. \\ ${ }_{4}^{4}$ Assistant Professor, Department of Plastic Surgery, Gandhi Medical College, Secunderabad.
}

\begin{abstract}
Mandible is the lower facial bone that plays an important role in complex function of chewing, deglutition, speech, supports Tongue and forms contour of lower third of Face. Rapid urbanization has resulted in increase in the number of road traffic ac cidents with fractures of the Facial bones. Mandible is the second most common facial bone to get fractured. Fractures of the Mandible need intervention at the earliest.
\end{abstract}

\section{AIM}

To retrospectively analyse the cause, age and sex incidence, sites of fracture of mandible, combination of fractures, various diagnostic and treatment modalities that were used.

\section{METHOD AND MATERIALS}

The study includes 1087 patients with isolated fractures of the mandible treated in the Department of Plastic Surgery at Gandhi Hospital between the years 2005 to 2014. The patterns of the history, clinical examination, diagnostic tests done were assessed. Age, sex, aetiology, method of management were the variables analysed. The statistical analysis was done using SPSS (Statistical Package for Social Sciences 0 Version 15.0 Statistical analysis software). The values are represented in frequencies and percentages.

\section{RESULTS}

1087 patients with isolated fractures of the mandible were studied. Steep rise in the incidence from $8.98 \%$ in 2005 to $18 \%$ in 2014 was noted. Males were more frequently involved (92.64\%) in comparison to females. The comm only involved age group was between 21-30 years (54.55\%). Most of the patients sustained injury due to road traffic accidents (75.9\%) of which majority were two wheeler accidents (45.81\%). Parasymphysis was fractured in $41.39 \%$. X-rays were used as the diagnostic modality between the years 2004 to 2010. Later digital X-rays and 3D Computerized Tomography have replaced it. Closed reduction was done in 57.22\%. Complications $(1.1 \%)$ in the form of infection and mal-occlusions were noted.

\section{DISCUSSION AND CONCLUSIONS}

The commonest aetiology was road traffic accidents and sense of public awareness is to be created about traffic rules and regulations. Males, age group between 21-30 and parasymphysis were commonly involved. Class I occlusion was achieved with closed method of Maxillomandibular fixation in 57.22\% and open reduction was done in cases where closed reduction was not possible and they amounted to $42.77 \%$.

\section{KEYWORDS}

Mandible Fracture, RTA, Parasymphysis, Closed Reduction, Open Reduction, MMF, Class I Occlusion.

HOW TO CITE THIS ARTICLE: Rangaswamy G, Kumar AS, Manjula G, et al. A retrospective study of epidemiology fractures of mandible in tertiary care teaching hospital over a period of a decade. J. Evolution Med. Dent. Sci. 2016;5(58):4011-4016, DOI: $10.14260 /$ jemds/2016/918

\section{INTRODUCTION}

Mandible is the lower facial bone that plays a central role in complex function of chewing, deglutition, speech, prevents collapse of upper airway by anterior fixation of hyoid bone and the hypopharynx, supports tongue and forms the contour of lower third of face. Fractures of mandible require urgent repair. A mention has been made about fracture of mandible in ancient Egypt as early as 1600 BCE - papyrus and later by Hippocrates (c.460 - c.370 BC).

Financial or Other, Competing Interest: None.

Submission 13-06-2016, Peer Review 08-07-2016,

Acceptance 14-07-2016, Published 20-07-2016.

Corresponding Author:

Gurram Rangaswamy,

Plot No. 244, 245, Block D,

RNS Dream Homes, RNS Colony,

Bouduppal, Hyderabad-500090,

Telangana, India.

E-mail: rangaswamyplastic@gmail.com

DOI: $10.14260 /$ jemds $/ 2016 / 918$
There has been rapid urbanization of Hyderabad in the past two decades with concomitant rise in the incidence of mandibular fractures. Our aim is to do a retrospective study of fractures of the mandible and analyse the data based on age, sex, aetiology, diagnostic and treatment modalities adopted on the patients who were treated in Gandhi Hospital, a tertiary care hospital, Secunderabad, over a decade from the year 2005 to 2014

\section{MATERIAL AND METHODS}

We did a retrospective analysis of all the patients admitted and treated for facial trauma during the period between 2005 and 2014. All the patients with isolated mandibular fractures had been included in the study. Those excluded from the study were patients with,

1. Polytrauma.

2. Maxillary and Zygoma fractures.

3. Unstable patients with Neurosurgery problems. 
Initially, all facio-maxillary patients were admitted in trauma care centre. Once they were stabilized, they were shifted to the Department of Plastic Surgery. Diagnosis was made on the basis of history, clinical examination and radiological examination. During the initial years of study from 2005 to 2010, plain X-ray mandible PA views alone were available. Digital X-ray mandible, plain Computerized Tomography (CT) and 3D Computerized Tomography (3D CT) scans were taken from mid-2010. The data was analysed based on age, sex, anatomical distribution, aetiological causes and management.

\section{RESULTS}

During the ten years' period from 2005 to 2014, faciomaxillary injuries were 1462 and isolated mandibular fractures were 1087 cases. The year-wise admissions of faciomaxillary and isolated mandibular fractures as shown in Graph-1 shows a steep increase in their numbers between the years from 2005 to 2014. The incidence has almost doubled. Admissions increased from $8.38 \%$ in 2005 to $18 \%$ in 2014 . Males were commonly involved and accounted for $92.64 \%$, while females constituted only $7.35 \%$ as shown in Graph 2. The most effected age group was 21-30 years in male and in females it was 10-21 years. The lowest affected age was a 2 years old male and in females it was 11 years old as shown in Graph 3.

The commonest cause of fractures was Road Traffic Accidents (RTA), which accounted to 75.9\%. Among them the two wheeler accidents accounted for $45.81 \%$ and the affected were under the influence of alcohol. Next commonest cause was four wheeler accidents to the extent of $36.52 \%$ followed by train accidents $(0.46 \%)$, fall from height $(2.29 \%)$ and trauma while walking under the influence of alcohol (4.04\%). There were work place accidents (1.37\%), human assaults $(9.01 \%)$ and animal assaults $(0.46 \%)$ too. None of the patients had sport injuries. Aetiological incidence is shown in Graph 4. Out of 895 cases of road traffic accidents which included two and four wheelers accidents, $82.32 \%$ were males and $5.40 \%$ were females; $0.5 \%$ of females had fractures following assaults for varied reasons. In fall from heights, $1.56 \%$ were males and $0.7 \%$ were females.

Alcohol had been a compounding factor for fractures. Out of 1087 patients, 576 (52.98\%) patients of fractures in Road Traffic Accidents (RTA), assaults and fall from height and selffall were under the influence of alcohol.

In our study, most common site of fracture was parasymphysis $(n=450)$ accounting to $41.39 \%$. Next common site was symphysis $(n=404)$ cases equating to $37.16 \%$. Bilateral fractures of various combinations were seen in 164 cases averaging $15.08 \%$. Multiple fracture sites of various combinations were seen in $(n=15) 1.37 \%$ cases. There was no significant difference between right (44.6\%) and left (45.4) side of the mandible. Out of 28 combinations, the most common type was parasymphysis of left side and angle of the opposite side in 90 cases (8.2\%) followed by both parasymphysis in 45 cases (4.1\%).

\section{Following are the other Fracture Combinations that were noted}

- $\quad$ Body and angle.

- Angle and parasymphysis.

- Sub-condylar and symphysis.
Methods of achieving Maxillomandibular fixation was either through eyelets alone or arch bars alone or a combination of both. Most of the patients were treated by closed reduction technique in 622 cases (57.22\%). Open reduction and internal fixation was done in $n=465$ cases $(42.77 \%)$.

\section{Closed Reduction Modalities Included}

- $\quad$ Cap splints - 4

- Gunning splints - 5

- Gilmer's wiring - 30

- Arch bars and Eyelets were used in both Closed and Open reduction.

- Arch bars in $\mathrm{n}=435$

- $\quad$ Eyelets in $=614$.

In the majority of cases, class I occlusion was attained with Maxillomandibular fixation done under local anaesthesia with $2 \%$ Lignocaine at a dosage of $3-5 \mathrm{mg}$ per $\mathrm{kg}$ body weight. In patients where Class I occlusion was not obtained with Maxillomandibular fixation, open reduction and internal fixation was done using $2 \mathrm{~mm}$ stainless steel plates and screws. Nasotracheal intubation was done in cases of open reduction and internal fixation. Endoscopic nasal intubation was done in 13 patients. After open reduction and internal fixation under General anaesthesia, Maxillomandibular fixation was done on the next day using stainless steel wires of 26 gauge or by rubber bands.

Most of the patients were discharged on third postoperative day and were followed every week in the Outpatient Department. Maxillomandibular fixation was removed after six weeks, but in cases of fractures of subcondylar region, it was removed within two weeks. In each follow-up visit, patient was assessed for occlusion, oral ulceration and oral hygiene, loosening of wires. All patients were advised liquid diet, mouth washes and brushing of tooth with paediatric brushes.

We did come across a few complications in 35 patients and the commonest complication was difficulty in opening the mouth. Graph 5 depicts various complications.

\section{DISCUSSION}

Globalization has made an impact on developing countries across the world and India is no exception for this, in particular Hyderabad the capital city of Telangana State in India. It has witnessed rapid and unplanned urbanization that has resulted in unprecedented growth of all types of motor vehicle on roads. The increase in vehicles has enabled increase in travel and transportation.

These findings of World Health Organization. ${ }^{1}$ exactly coincide with our findings. The year-wise admission of faciomaxillary cases has been increasing in our department from year 2005 (10\%) to $21.23 \%$ in year 2014 and during the same period isolated fractures of mandible too increased from $8.98 \%$ in 2005 to $18 \%$ in 2014 .

In this study, diagnosis of fracture was based on clinical examination and plain X-ray mandible PA view from 2005 to 2010. Later plain Computerized Tomography and 3D Computerized Tomography and digital X-rays are being used for diagnosis. Computed tomography is the most sensitive and specific imaging technique. The facial bones were visualized as slices in the axial, coronal or sagittal planes. Images can be reconstructed into a 3-dimensional view to give a better idea 
of the displacement of various fragments. The results of our study regarding age also correlated with the study in India and abroad.

Males are the most commonly affected (92.64\%) in our study as is noticed in the studies by Abdurrazaq Olanrewaju Taiwoin. ${ }^{2}$ (95\%) in Arif Rashid (87\%).3, Marcelo ZilloMartini et al (87\%). ${ }^{4}$ and in Subodh Natu et al ${ }^{5}(81.8 \%)$.

The observed ratio between male and females in our series is $13: 1$, and it is similar in the studies by Subodh S. Natu, et $\mathrm{al}^{5}$ (4.5:1), K. Subhashraj, et al $^{6}$ (5.1:1), Alexander J. Sojat, BSc. ${ }^{7}$ et al (5:1). Males being the bread earners for the family venture out and are getting involved in the trauma and this could be the reason for the male preponderance. Most common age group involved in our study is between 21-30 years (43.5\%). Our study matches with that of Dhananjay Barde et al 8 (37.5\%), Wasiu L. Adeyemo, et al $^{9}$ (49.3\%). Females were commonly affected between 11-20 years. Dr. Marcelo ZilloMartini et al, Alexander J. Sojat et al studies also showed the same age pattern in their study, but in Kelly Marinho et al ${ }^{10}$ series females aged between 30-40 years were commonly affected.

There is marked difference in aetiology of fracture mandibles both in the developed and developing countries. The commonest cause in developing countries is road traffic accidents. Our study is in accordance with the other study groups of Adi et al ${ }^{11}$, Bataineh ${ }^{12}$, Shah et al ${ }^{13}$ Ahmed et al $^{14}$ and Brasileiro and Passeri. ${ }^{15}$ wherein road traffic accidents are the commonest cause for mandibular fractures. Interpersonal violence. ${ }^{3}$ in the form of assault, Gunshot injuries had replaced road traffic accidents in developed countries like Europe, Australia and America. Other studies have reported assault.7,16,17,18 as the main causative factor for fracture of mandible. According to Taher and Olasoji et al ${ }^{19}$ fractures caused by firearms and assault appear to be the main cause of facial fractures in North Eastern Nigeria. There are no fractures due to bullet injuries in our study.

Telangana and in particular Hyderabad has the highest number of two wheelers in India. Krishnaraj S.20 et al (73\%) states that the motor cycle accidents. ${ }^{12,21-26}$ as the commonest cause of fractures of the mandible. Overspeeding due to urgency to reach the work place in the rush hours and to reach home in the night on the two wheelers are the reasons. Motor cycles have become the cheapest means of transport for their goods. Overloading with three to five members, drunken driving at night, tiredness are other causes for accidents.

Rampant opening of Government run belt shops, wine shops along highways have been found to be leading to the accidents. Most of the people affected were low and middle class income groups. Alcoholism was responsible for the accidents due to four wheeler, two wheeler, assaults, fall from height and self-falling, and it was noted in $52.99 \%$ of the total cases. Heimdahl A, et al27,28,29 study, in Sweden, has reported Alcohol or narcotic involvement in mandibular fractures to be as high as $56 \%$ and most of the cases were associated with violence (79\%), which were linked to alcohol abuse. In the study by V. Ravindran et $\mathrm{al}^{30}$ from Kerala, alcoholism was reported as a compounding factor in $34.61 \%$.

The most frequent cause of facial trauma in Marcelo ZilloMartini et al series states that traffic accidents with motor cycles is $17.7 \%$ and with four wheelers accidents it is $15.4 \%$.

The most common site of fracture noted in our series is Parasymphysis (41.39\%). Parasymphysis is a common site due to the length of canine, which results in weakening of the bone. Our study is consistent with other study groups like Vibha et al (45.25\%), Dhananjaya, Barde et al ( $41.1 \%$ ), Sourab et al (39.3\%), Krishnaraj S (37.7\%), Snehal and Bansed (31.97\%), Sunita Malik et al (23.25\%), Subhas raj et al (35\%). Ellis et al and Malisba et al who found that the body followed by condyle to be the most common site of fracture in their study. Bilateral fractures occurred in $15.08 \%$ and there are varying combinations. There is no significant difference between right (44.6\%) and left (45.4\%) side of the mandibles. Our study is in confirmation with the study by Sunita Malik et al, who reported the incidence at $48.81 \%$ and $51.2 \%$ for right and left sides respectively.

Our method of achieving class I occlusion was by Maxillomandibular fixation through closed reduction in $(n=622)$ cases $(57.22 \%)$ and open reduction was done in $n=$ 465 cases $(42.78 \%)$. Treatment modality adopted is shown in Table 3. We used the Eyelets for achieving Maxillomandibular fixation, as it is less time consuming. Due to the enormous workload, we are compelled to do closed reduction with simple Maxillomandibular fixation. The same was noticed in the studies by Wasiu L. Adeyemo (83.1\%), Marcelo ZilloMartini et al (59.37\%) and Alexander J. Sojat et al (50.8\%). In cases where there is loss of anterior tooth, we used the Gilmer's technique to achieve Maxillomandibular fixation.

All sub-condylar fractures were treated with simple Maxillomandibular fixation, which was retained for 2 weeks. Our study correlates with that of Nicholas Zachariadei et $\mathrm{al}^{31}$ in conservative management of Sub-condylar fractures. Marker et al found that conservative closed reduction for the treatment of condylar fractures is safe, cost effective, nontraumatic and reliable. In the study of the Santler et al ${ }^{32}$ two hundred and thirty four patients with fractures of the mandibular condylar process were treated by Open or Closed methods. No significant difference in mobility, joint problems, occlusion, muscle pain or nerve disorders were noted in the patients treated by either Open or Closed method.

In our study patients who were un-cooperative, edentulous, open reduction and internal fixation was done using $2 \mathrm{~mm}$ plates with six holes and $2 \mathrm{~mm}$ screws were used. Maxillomandibular fixation with titanium plates and screws has gained popularity and has become the gold standard procedure world-wide, but ours being public sector hospital, the high cost of Titanium implants has become a prohibitive factor for their use. In 25 cases, we used 26 G stainless steel wire for achieving reduction of fractured segments.

We did come across some complications. Post-operative oedema was common in all cases of open reduction and internal fixation. Infection was seen in 12 cases and presented with sinus. They were treated with oral antibiotics, Ciprofloxacin $500 \mathrm{mg}$ twice daily and Metrogyl $500 \mathrm{mg}$ thrice daily for one week followed by removal of the interosseous wires in eight cases and plates in five cases. Malocclusion was seen in six cases with Maxillomandibular fixation of Symphysis alone and Symphysis and Sub-condylar fractures.

All patients with lingual bites were reopened and open reduction and internal fixation was done. Our series showed $3.21 \%$ of complications in the form of infection $(n=12)$, malocclusion $(n=6)$, difficulty in mouth opening $(n=15)$ and mortality $(\mathrm{n}=2)$. Other studies reported complications in 19.8\%.4 5.3\%.7 13\%.28 (Bochlogyros PN, et al) $21.5 \% .{ }^{29}$ (Wagner WF et al) of the patients. Difficulty in mouth opening 
was seen in 15 cases. Initially, exercises of temporomandibular were explained to the patients. If the mouth opening did not improve despite physiotherapy, mouth dilatation with Heisters dilator was used in five cases. We noticed two deaths in our study. One patient died due to grossly infected comminuted fracture mandible. He was Diabetic, Hypertensive and developed Aspiration pneumonitis. Postmortem analysis in another patient revealed splenic rerupture and massive intra-abdominal bleed. This patient was readmitted one month after discharge from General Surgery Department.

\section{CONCLUSIONS}

The results of our study indicate that the accidents involving the two wheeler accidents as the main cause for fractures of the mandible followed by the four wheelers accidents. Parasymphysis was the commonest site for fracture. Majority of them were males aged between 21 and 30 years. Most of the cases were managed with closed reduction techniques. Class I occlusion with Maxillomandibular fixation was achieved using IVY method of Eyelet technique. Nearly 40 percent of cases of closed reduction were done under Regional anaesthesia.

The existing legislations should be reassessed and made more rigid. Government should develop social marketing campaigns and measure their impact. They should host workshops and provide road safety equipment. The police should be trained to enforce the legislations. The NonGovernmental Organizations should be involved to decrease the accidents. The mind-set of the people needs to be changed for the benefit of their own family and for the society at large.

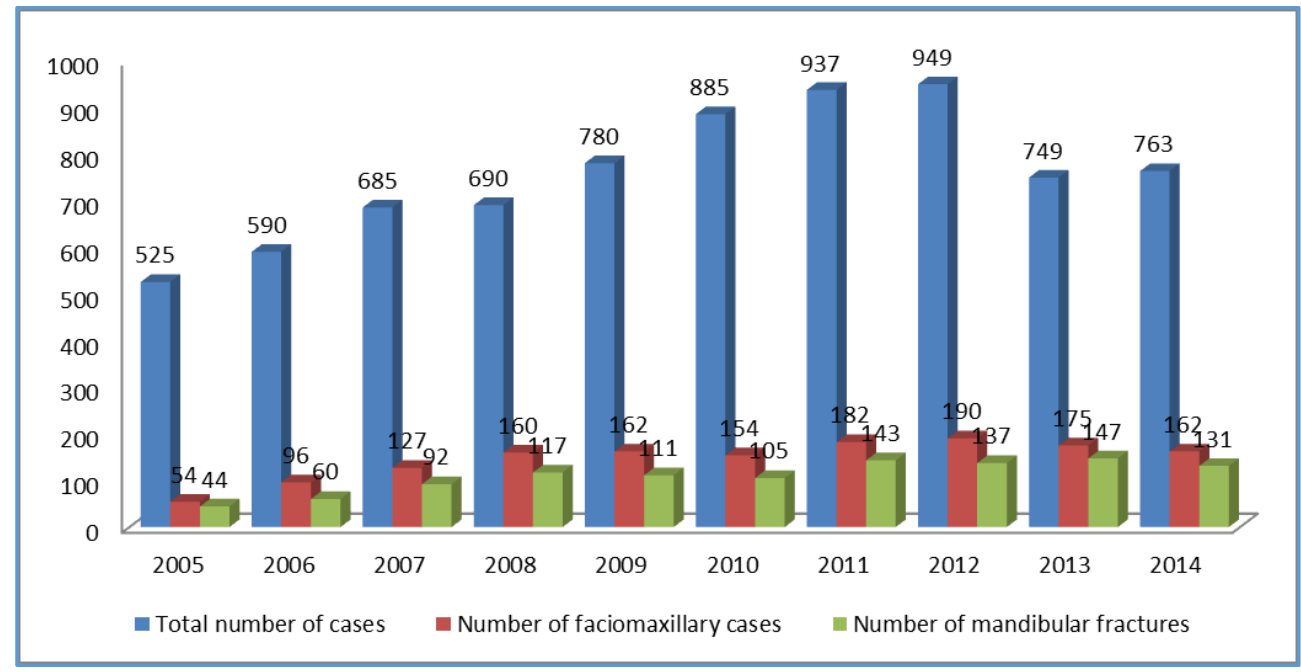

Graph 1: Incidence of Admissions of Mandibular Fractures

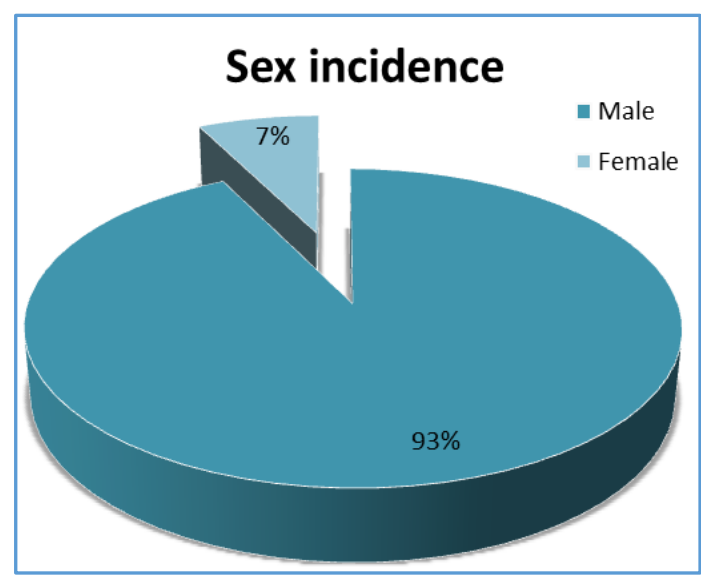

Graph 2: Incidence Gender-Wise

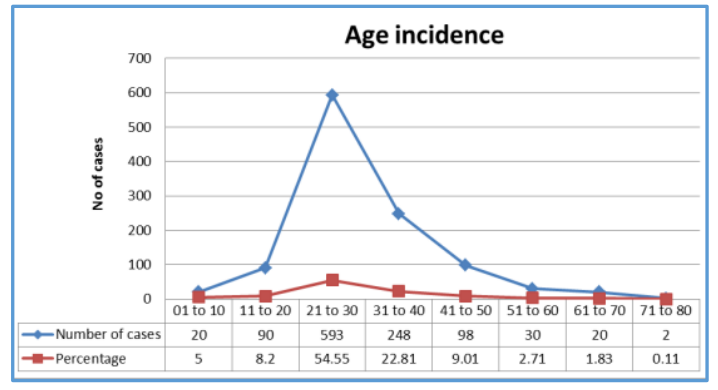

Graph 3: Age-Wise Incidence

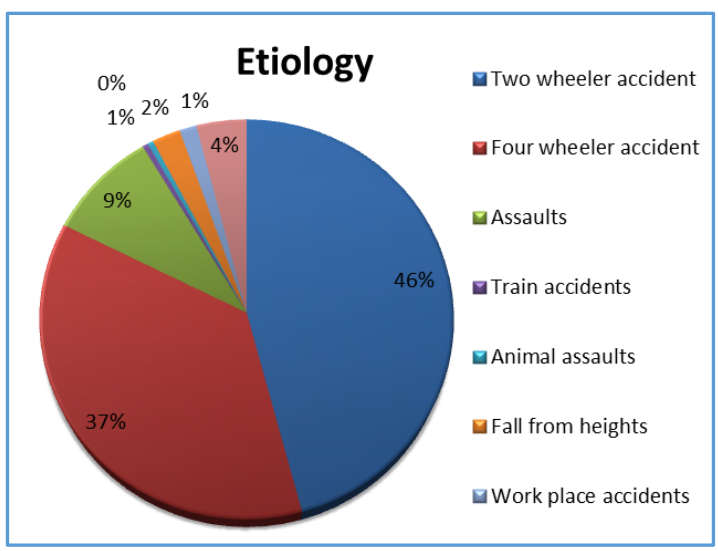

Graph 4: Aetiology

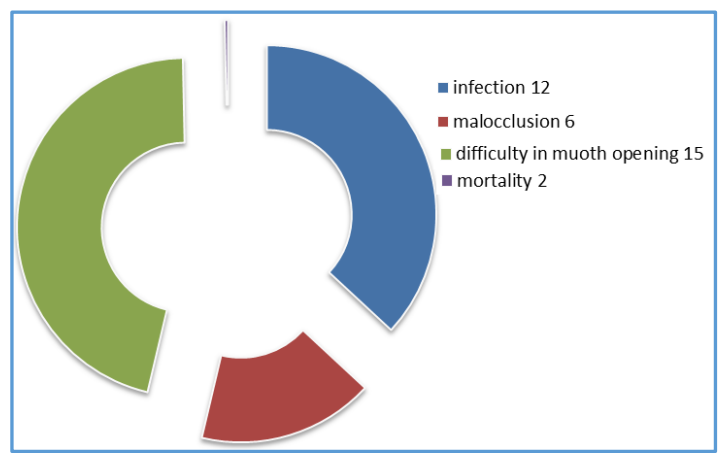

Graph 5: Complications 


\begin{tabular}{|c|c|c|}
\hline $\begin{array}{l}\text { Anatomical Site } \\
\text { of Fracture }\end{array}$ & $\begin{array}{l}\text { No. of } \\
\text { Cases }\end{array}$ & Percentage \\
\hline Symphysis & 404 & 37.16 \\
\hline Parasymphysis & 450 & 41.39 \\
\hline Both Parasymphysis & 45 & 4.13 \\
\hline Symphysis and Parasymphysis & 6 & 0.55 \\
\hline Pure sub-condylar & 10 & 0.91 \\
\hline Symphysis with sub-condyle & 5 & 0.4 \\
\hline Symphysis with dentoalveolus & 5 & 0.4 \\
\hline Symphysis with angle & 4 & 0.36 \\
\hline $\begin{array}{l}\text { Parasymphysis with } \\
\text { dentoalveolus }\end{array}$ & 8 & 0.7 \\
\hline Angle only & 19 & 1.7 \\
\hline Angle and body & 6 & 0.5 \\
\hline Only alveolus & 24 & 2.20 \\
\hline $\begin{array}{l}\text { Parasymphysis with bilateral } \\
\text { sub-condyles }\end{array}$ & 4 & 0.36 \\
\hline Angle and ramus & 7 & 0.64 \\
\hline Parasymphysis + angle & 82 & 7.54 \\
\hline Coronoid process & 8 & 0.7 \\
\hline
\end{tabular}

11. Adi M, Ogden GR, Chisholm DM. An analysis of mandibular fractures in Dundee, Scotland (1977 to 1985). Br J Oral Maxillofac Surg 1990;28(3):194-9.

12. Bataineh $\mathrm{AB}$. Aetiology and incidence of maxillofacial fractures in the north of Jordan. Oral Surgery Oral Medicine Oral Pathology Oral Radiology Endodontics 1998;86(1):31-5.

13. Dongas $\mathrm{P}$, Hall GM. Mandibular fracture patterns in Tasmania, Australia. Australian Dental Journal 2002;47(2):131-7.

14. Ahmed HEA, Jaber MA, Fanas SHA, et al. The pattern of maxillofacial fractures in Sharjah, United Arab Emirates: a review of 230 cases. Oral Surgery Oral Medicine Oral Pathology Oral Radiology and Endodontology 2004;98(2):166-70.

15. Brasileiro BF, Passeri LA. Epidemiological analysis of maxillofacial fractures in Brazil:a 5-year prospective study. Oral Surgery Oral Medicine Oral Pathology Oral Radiology and Endodontology 2006;102(1):28-34.

16. Ellis E, Moos KF, el-Attar A. Ten years of mandibular fractures: an analysis of 2,137 cases. Oral Surg Oral Med Oral Pathol 1985;59(2):120-9.

17. Marker P, Nielsen A, Bastian HL. Fractures of the mandibular condyle. part 1: patterns of distribution of types and causes of fractures in 348 patients. Br J Oral Maxillofac Surg 2000;38(5):417-21.

18. Oikarinen K, Ignatius E, Kauppi H, et al. Mandibular fractures in northern Finland in the 1980s-a 10-year study. Br J Oral Maxillofac Surg 1993;31(1):23-7.

19. Olasoji HO, Tahir A, Arotiba GT. Changing picture of facial fractures in northern Nigeria. Br J Oral Maxillofac Surg 2002;40(2):140-3.

20. Krishnaraj S, Chinnasamy R. A 4-year retrospective study of mandibular fractures in a south Indian city. J Craniofac Surg 2007;18(4):776-80.

21. Marker $P$, Nielsen A, Bastian HL. Fractures of the mandibular condyle. Part 2: results of treatment of 348 patients. British Journal of Oral and Maxillofacial Surgery 2000;38(5):422-6Ugboko VI, Odusanya SA, Fagade 00. Maxillofacial fractures in a semi-urban Nigerian teaching hospital a review of 442 cases. Int J Oral Maxillofac Surg 1998;27(4):286-9.

22. Tanaka N, Tomitsuka K, Shionoya K, et al. Aetiology of maxillofacial fracture. $\mathrm{Br} \mathrm{J}$ Oral Maxillofac Surg 1994;32(1):19-23.

23. Tay AG, Yeow VK, Tan BK, et al. A review of mandibular fractures in craniomaxillofacial trauma centre. Ann Acad Med Singapore 1999;28(5):630-3.

24. Oji C. Jaw fractures in Enugu, Nigeria, 1985-95. Br J Oral Maxillofac Surg 1999;37(2):106-9.

25. Adams CD, Januszkiewcz JS, Judson J. Changing patterns of severe craniomaxillofacial trauma in Auckland over eight years. Austr N Z J Surg 2000;70(6):401-4.

26. Heimdahl A, Nordenram A. The first 100 patients with jaw fractures at the department of oral surgery, dental school, Huddinge. Swed Dent J 1977;1(5):177-82.

27. Bochlogyros PN. Retrospective study of 1,521 mandibular fractures. J Oral and Maxillofac Surg 1985;43(8):597-9.

28. Wagner WF, Neal DC, Alpert B. Morbidity associated with extra oral open reduction of mandibular fractures. J Oral Surg 1979;37(2):97-100. 
29. Ravindran V, Nair KSR. Meta-analysis of maxillofacial trauma in the northern districts of Kerala: one year prospective study. J Maxillofacial Oral Surg 2011;10(4): 321-7.

30. Zachariades N, Mezitis M. Fractures of the mandibular condyle: a review of 466 cases literature review, reflections on treatment and proposals. Journal of CranioMaxillofacial Surgery 2006;34(7):421-32.
31. Santler G, Kärcher H, Ruda C, et al. Fractures of the condylar process: surgical versus nonsurgical treatment. J Oral Maxillofac Surg 1999;57(4):392-7 